\title{
Pulmonary Functions and Factors Affecting Them in Patients with Chronic Kidney Disease
}

\author{
Muhammad Anees ${ }^{1}$, Hina Akbar ${ }^{1}$, Muhammad Ibrahim³ ${ }^{3}$ Muhammad Saqib Saeed ${ }^{2}$ and Minahil Ismail ${ }^{4}$ \\ ${ }^{1}$ Department of Nephrology, King Edward Medical University, Lahore, Pakistan \\ ${ }^{2}$ Department of Pulmonology, King Edward Medical University, Lahore, Pakistan \\ ${ }^{3}$ Department of Statistics, King Edward Medical University, Lahore, Pakistan \\ ${ }^{4}$ Department of Nephrology, Mayo Hospital, Lahore, Pakistan
}

\begin{abstract}
Objective: To determine the pulmonary functions in patients with chronic kidney diseases (CKD) and factors affecting them.

Study Design: Observational study.

Place and Duration of Study: Nephrology Department, Mayo Hospital, Lahore, from October 2018 to April 2019.

Methodology: All patients of CKD, coming in Nephrology OPD, were included. Patients on maintenance hemodialysis (HD), chronic obstructive pulmonary disease (COPD), smokers, chronic heart disease, and neuromuscular diseases were excluded from the study. Demographic data, physical examination findings and laboratory parameters were taken. Patients underwent spirometry at Pulmonology Department for measurement of forced expiratory volume in the first second (FEV1), forced vital capacity (FVC) and FEV1/FVC.

Results: One hundred and forty patients were included in the study. Mean GFR was $27.75 \pm 17.49 \mathrm{ml} / \mathrm{min} / 1.73 \mathrm{~m}^{2}$ and $7(5 \%)$ patients belonged to stage 2 CKD, 48 (34.3\%) belonged to stage 3 CKD, 45 (32.1\%) belonged to stage 4 CKD and rest $40(28.6 \%)$ were from stage 5 CKD. Pulmonary functions were FEV1 $(90.81 \pm 25.84)$, FVC $(88.91 \pm 28.54)$, and FEV1/FVC (108.57 \pm 13.0$)$. According to laid down criteria, 62 (44.3\%) cases had restrictive lung disease (RLD), 5 (3.6\%) cases had mixed and $78(55.7 \%)$ cases normal lung function status. Important factors affecting pulmonary functions were GFR $(p=0.038)$, monthly income $(p=0.017)$ and education $(p=0.041)$. Drop in GFR and anemia have negative correlation and age has positive correlation with pulmonary dysfunctions.

Conclusion: Pulmonary functions were abnormal in almost half of the patients and restrictive lung disease was the most common pattern in these patients. Factors affecting the pulmonary functions were progression of CKD, falling hemoglobin level, monthly income and education. Drop in GFR and anemia had negative correlation and age had positive correlation with pulmonary functions.
\end{abstract}

Key Words: CKD, Pulmonary functions, Restrictive lung disease, GFR, Anemia.

How to cite this article: Anees M, Akbar H, Ibrahim M, Saeed MS, Ismail M. Pulmonary Functions and Factors Affecting Them in Patients with Chronic Kidney Disease. J Coll Physicians Surg Pak 2020; 30(10):1082-1085.

\section{INTRODUCTION}

Chronic kidney disease (CKD), a well-known global health issue, is defined as the structural or functional damage for $\geq 3$ months with glomerular filtration rate (GFR) $<60 \mathrm{ml} / \mathrm{min} / 1.732$ $\mathrm{m}^{2}$ irrespective of the cause. ${ }^{1}$ It is a syndrome involving multiple organs and not just a localised disease. Respiratory system may be severely affected by advanced CKD. ${ }^{2}$

Correspondence to: Dr. Muhammad Anees, Department of Nephrology, King Edward Medical University, Lahore, Pakistan

E-mail: dranees109@hotmail.com

Received: February 06, 2020; Revised: July 15, 2020;

Accepted: July 24, 2020

DOI: https://doi.org/10.29271/jcpsp.2020.10.1082
According to the National Health and Nutrition Examination Survey (NHANES) 2007-2012, ${ }^{3}$ the prevalence of lung dysfunction is increased with deteriorating kidney function from stage 1 to stage 4 CKD, with $10 \%$ for restrictive lung disease (RLD) and $16 \%$ for obstructive lung disease (OLD). Lung dysfunctions are divided into restrictive, obstructive and mixed lung disease, depending on the spirometric measurements. According to literature, RLD is more common in patients with CKD. ${ }^{4}$ There are many reasons for this type of pattern, like falling GFR, pulmonary edema, respiratory muscle dysfunction, ${ }^{5,6}$ pulmonary fibrosis, pulmonary calcification, pulmonary hypertension, hemosidrosis and pleaural fibrosis. Even the urinary protein excretion with normal kidney function is associated with development of pulmonary dysfunctions ${ }^{7}$.Pulmonary dysfunctions not only affect quality of life, but even increases mortality of CKD patient. ${ }^{8,9}$ 
Table I: Demographic and clinical data affecting lung functions.

\begin{tabular}{|c|c|c|c|}
\hline \multicolumn{3}{|l|}{ Lungs functions } & \multirow[b]{2}{*}{ p-value } \\
\hline Parameters & $\begin{array}{c}\text { Normal lungs } \\
77(55 \%)\end{array}$ & \begin{tabular}{|c|} 
Restrictive \\
lungs disease \\
$63(45 \%)$
\end{tabular} & \\
\hline $\begin{array}{l}\text { Age (years) } \\
<30 \\
30-60 \\
>60\end{array}$ & $\begin{array}{c}10(7.1 \%) \\
51(36.4 \%) \\
16(11.4)\end{array}$ & $\begin{array}{c}6(4.3 \%) \\
48(34.3 \%) \\
9(6.4 \%)\end{array}$ & 0.434 \\
\hline $\begin{array}{l}\text { Gender } \\
\text { Male } \\
\text { Female }\end{array}$ & $\begin{array}{l}39(27.9 \%) \\
38(27.1 \%)\end{array}$ & $\begin{array}{l}25(17.9 \%) \\
38(27.1 \%)\end{array}$ & 0.195 \\
\hline $\begin{array}{l}\text { Monthly income (Rs) } \\
<10,000 / \text { Month } \\
10,000-30,000 \\
>30,000\end{array}$ & $\begin{array}{c}48(34.3 \%) \\
23(16.4 \%) \\
6(4.3 \%)\end{array}$ & $\begin{array}{c}53(37.9 \%) \\
8(5.7 \%) \\
2(1.4 \%) \\
\end{array}$ & $0.017 *$ \\
\hline $\begin{array}{l}\text { Education } \\
\text { Illiterate } \\
<5^{\text {th }} \text { Grade } \\
5-10^{\text {th }} \text { Grade } \\
>10^{\text {th }} \text { Grade }\end{array}$ & $\begin{array}{l}24(17.1 \%) \\
16(11.4 \%) \\
23(16.4 \%) \\
14(10.0 \%)\end{array}$ & $\begin{aligned} 29 & (20.7 \%) \\
7 & (5.0 \%) \\
23 & (16.4 \%) \\
4 & (2.9 \%)\end{aligned}$ & $0.041 *$ \\
\hline $\begin{array}{l}\text { Cause of CKD } \\
\text { Diabetes } \\
\text { Non diabetes }\end{array}$ & $\begin{array}{l}26(18.6 \%) \\
51(36.4 \%)\end{array}$ & $\begin{array}{l}28(20.0 \%) \\
35(25.0 \%)\end{array}$ & 0.197 \\
\hline $\begin{array}{l}\text { Ex-smokers } \\
\text { Yes } \\
\text { No }\end{array}$ & $\begin{array}{l}25(17.9 \%) \\
52(37.1 \%)\end{array}$ & $\begin{array}{l}18(12.9 \%) \\
45(32.1 \%)\end{array}$ & 0.619 \\
\hline $\begin{array}{l}\text { Hemoglobin }(\mathrm{g} / \mathrm{dl}) \\
\geq 11 \\
<11 \mathrm{gm}\end{array}$ & $\begin{array}{l}44(31.4 \%) \\
33(23.6 \%)\end{array}$ & $\begin{array}{l}26(18.6 \%) \\
37(26.4 \%)\end{array}$ & 0.062 \\
\hline $\begin{array}{l}\text { GFR }\left(\mathrm{ml} / \mathrm{min} / 1.73 \mathrm{~m}^{2}\right) \\
<15 \\
>15\end{array}$ & $\begin{array}{l}17(12.1 \%) \\
60(42.9 \%)\end{array}$ & $\begin{array}{l}24(17.1 \%) \\
39(27.9 \%)\end{array}$ & $0.038 *$ \\
\hline
\end{tabular}

Pulmonary functions are not routinely addressed by nephrologists despite its high prevalence. This is the first study to the best of authors knowledge conducted in Pakistan to highlight this important but neglected aspect of CKD patients.

The objective of this study was to determine the types of pulmonary dysfunctions in patients with CKD and factors affecting them. Finding of this study may be useful for future reference and implemenatation of interventions.

\section{METHODOLOGY}

This study was conducted at Nephrology Department, Mayo Hospital, Lahore in collaboration with Pulmonology Department from October 2018 to April 2019 aftertaking approval from Institution Review Board of the University. The study was conducted in adherence to the Declaration of Helsinki. ${ }^{10}$ All patients who were coming in Nephrology OPD and fulfilled the inclusion criteria were enrolled in the study after taking informed consent. Patients who were on hemodialysis, having active and chronic lung disease, chronic heart disease, chronic liver disease, and with neuromuscular disorders were excluded from the study. Demographic data containing age, gender, level of education, socio-economic status and history of CKD was entered in predesigned form. Physical examination of patient's data containing blood pressure, body mass index (BMI) and volume status was also entered in the proforma. Blood samples were sent to laboratory to measure the amount of hemoglobin, serum urea, creatinine and GFR was determined by Modification of Diet in Renal Disease (MDRD) formula. ${ }^{11} \mathrm{CKD}$ staging was done according to established criteria by KDIGO guidelines. ${ }^{12}$ Patients underwent spirometry at Pulmonology Department for measurement of FEV1, forced vital capacity (FVC), FEV1/FVC. On the basis of already laid down criteria, lung functions were divided into normal, restrictive and obstructive pattern. ${ }^{13}$ Factors affecting pulmonary functions were also determined.

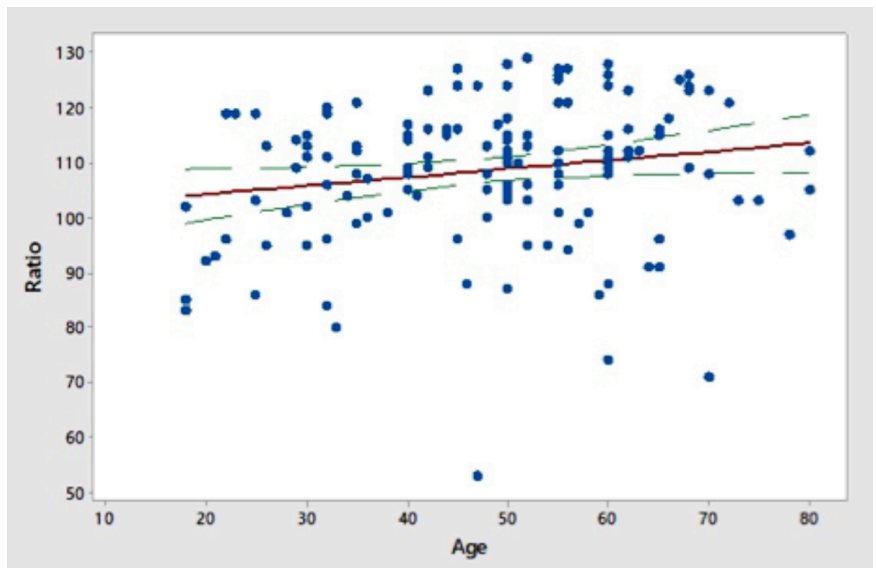

Figure 1 (A): Correlation of pulmonary functions (restrictive lung disease) and age.

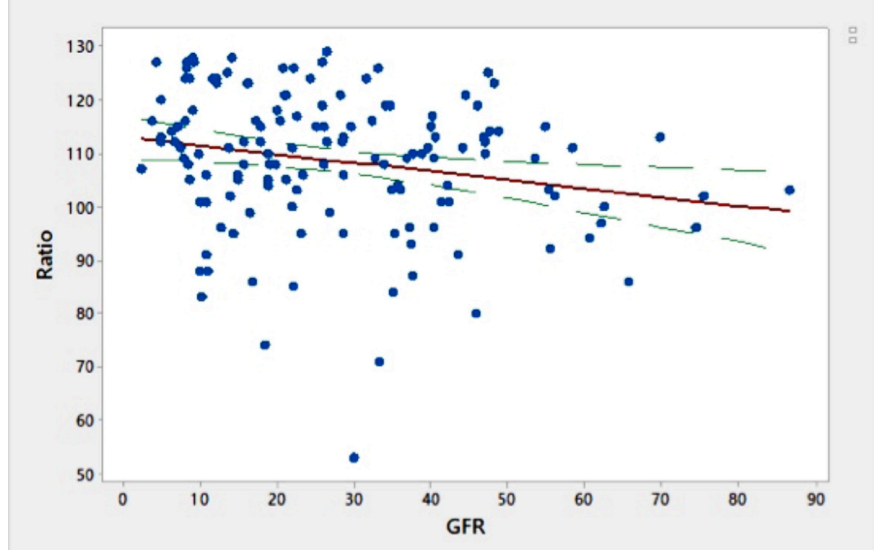

Figure 1 (B): Correlation of pulmonary functions (restrictive lung disease) and GFR (falling kidney functions).

Descriptive statistics was used in the form of summary measures for categorical variables as well as continuous variables. For categorical variables, i.e. gender, smokers, RLD, OLD and mixed lung disease, percentages (proportion) were used. For continuous variables, e.g. age, duration, CKD, GFR value, mean and standard deviation were reported. Data was stratified for age, gender duration of CKD and GFR value and smoker. Chi-square test was used for measuring any association between variables and taking $p$-value $\leq 0.05$ as significant. Statistical analysis was made using SPSS version 22.0 (SPSS Inc. Chicago, IL, USA). Pearson correlation coefficient was also employed to determine the relationship between variables.

\section{RESULTS}


One hundred and forty patients were included in the study. The mean age of patients was $48.06 \pm 14.59$ years and the majority of patients were males 76 (54.3\%) and rest were females 64 (45.7\%). Majority of the patents were illiterate or less than five grade of education and belonged to poor socio-economic status (monthly income less than Rs.10000/month). Diabetes mellitus (DM, $n=65$, $46.4 \%$ ) was the leading cause of CKD followed by hypertension (HTN, $n=44,31.4 \%$ ). The mean weight, height and BMI were 61.84 $\pm 2.26 \mathrm{Kg}, 1.59 \pm 0.02 \mathrm{~m}$ and $24.33 \pm 1.16 \mathrm{Kg} / \mathrm{m}^{2}$, respectively. Mean GFR was $27.75 \pm 17.49 \mathrm{ml} / \mathrm{min} / 1.73 \mathrm{~m}^{2}$ and 7 (5\%) patients belonged to stage 2 CKD, 48 (34.3\%) belonged to stage 3 CKD, 45 (32.1\%) belonged to stage 4 CKD and rest $40(28.6 \%)$ had stage 5 CKD. Mean duration of CKD was $30.83 \pm 50.04$ months. There were 43(30.7\%) ex-smokers and 97 (69.3\%) non-smokers.

Pulmonary function values for FEV1, FVC, FEV1 /FVC were $90.81 \pm$ $25.84,88.91 \pm 28.54,108.57 \pm 13.0$, respectively. According to the laid down criteria, 62 (44.3\%) cases had RLD, 5 (3.6\%) cases had mixed and 78 (55.7\%) cases normal lung function status. Important factors affecting pulmonary functions were GFR $(p=0.038)$, monthly income $(p=0.017)$ and education $(p=0.041)$. Drop in GFR and anemia had negative correlation and age had a positive correlation with pulmonary functions. Factors not affecting PFTs were hemoglobin $(0.062)$, age $(p=0.434)$, gender $(p=0.195)$, cause of CKD $(p=0.197)$ and smokers vs non-smokers $(p=0.619)$ as shown in Table I. Statistically significant positive correlation was found between age and restrictive lung disease $(r=0.174, p=0.040)$. Falling kidney functions $(-0.216, p=0.011)$ and drop in hemoglobin $(-0.228, p=0.007)$ were negatively correlated while age was positively correlated with RLD, as shown in Figure 1.

\section{DISCUSSION}

In this study, most common lung dysfunction was RLD as observed in other international studies; ${ }^{14}$ but in contrast with other studies, mixed and obstructive lung diseases were more prevalent. The reason for this difference may be that we have excluded the patients who stopped smoking about 10 years back and patients with history of any acute and chronic obstructive pulmonary pathology, while other study did not excluded these patients. There are multiple factors for restrictive type of lung functions in patients with CKD, like cardiovascular disease, protein energy malnutrition, inflammation, volume overload, accumulation of uremic toxins, electrolyte disorders and acid/ base imbalance. ${ }^{15}$ In this study, negative correlation was observed between fall in GFR and lung dysfunctions. Similar pattern of the progression of CKD and lung dysfunctions are observed in another study from Korea. ${ }^{16}$ According to that study, multivariate linear regression analysis showed a decline in GFR, which was independently associated with fall in percent predicted FVC and FVC1/FVC ratio amongst both men and women; whereas, respiratory muscle weakness and protein energy malnutrition was closely related with pulmonary dysfunctions. The authors did not study the status of malnutrition and hypoalbuminemia in these patients; and there is need to conduct further studies for the correlation of these factors in future.

In this study, patients belonging to lower-middle socio-economic class were having more RLD as compared to upper class of patients. Pakistan is a developing country where gross domestic product (GDP) per capita income is $\$ 1357$ dollar as compared to developed country like USA, where GDP per capita is \$ $62606 .{ }^{17}$ Due to lower income status, poor patients cannot afford early detection of CKD; and if diagnosed, cannot manage properly for the progression of the disease and ends up with ESRD at very younger age. Along with these problems, low birth weight babies, poor mental health, communicable diseases, hazardous working environment, lack of social protection, access to nephrology services and unhygienic housing conditions are also risk factors for these diseases. Financial status is a very important factor affecting socio-economic and health-related quality care. Similar observation was made previously ${ }^{18}$ in which patients belonging to lower economic class were having high mortality than patients belonging to upper class.

In this study, CKD patients who were having higher education level and spent more years in school and college were having normal lung functions than patients with lower level of education. The main reason is that education gives awareness, better understanding of the diseases and treatment options, which improve the compliance to treatment. Moreover, the educated people have an early access to nephrology services because social and print media help them a lot in getting an access to nephrologist. Educated patients start treatment early and they remain adherent to the prescription of the treating physicians. Due to the strict compliance and adherence to treatment, progression of the CKD is well controlled and lung functions remain normal even at laterstage of the disease.

In this study, mean hemoglobin was $10.46 .21 \mathrm{gm} / \mathrm{dl}$ and almost $50 \%$ of the patients were anemic. Patients who were anemic were having RLD as compared to patients with normal hemoglobin level. In present study, falling hemoglobin was having negative correlation with pulmonary functions. Actually, hemoglobin helps in carrying oxygen to the tissues and patients with less hemoglobin level has deficiency in carrying capacity of oxygen; and it presents with RLD. CKD patients have high prevalence of anemia and its prevalence is directly related with progression of kidney diseases. ${ }^{19}$ Even the $45 \%$ of general population of Pakistan is suffering from iron deficiency anemia, ${ }^{20}$ realising the failure of the public health measures to control it. There is need to focus this important aspect of CKD patients; and anemia must be corrected through iron, folic acid and vitamin B12 replacement along with the Erythrpoitin (EPO) injections, if there is need. As anemia not only affect cardiac manifestations in these patients but even the quality of the life is hampered leading to very high morbidity and mortality of these patients.

\section{CONCLUSION}

Pulmonary functions were abnormal in almost half of the patients and restrictive lung disease was the most common pattern in those patients. Factors affecting the pulmonary functions were progression of CKD, increasing age and falling hemoglobin level.

\section{ETHICAL APPROVAL:}

The paper is compliant with ethical framework and guidelines of the institution in relation with publication of medical research.

\section{PATIENTS' CONSENT:}


This study was conducted after obtaining informed consents from the patients.

\section{CONFLICT OF INTEREST:}

Authors declared no conflict of interest.

\section{AUTHORS'CONTRIBUTION:}

MA: Main idea, concept framework and final write-up, drafting the work or revising it critically forimportant intellectual contents.

HA: Data collection.

MSS: Supervision of pulmonary function tests procedures.

MI: Statistical data analysis.

MI: Literature review and referencing.

\section{REFERENCES}

1. Kidney disease: Improving global outcomes (KDIGO) CKDMBD work groupkdigo clinical practice guideline for the diagnosis, evaluation, prevention, and treatment of chronic kidney disease-mineral and bone disorder (CKD-MBD). Kidney Int 2009; Suppl S1-130.

2. Rezaeetalab F, Zeraati A, Fadaeian AH, Akbarirad MA, Ghazaleh S, MohamadZadeh L, et al. Spirometric parameters: Hemodialysis compared to peritoneal dialysis. J Cardiothorac Med 2015; 3(2):293-6.

3. Navaneethan SD, Mandayam S, Arrigain S, Rahman M, Winkelmayer WC, Schold JD. Obstructive and restrictive lung function measures and CKD: National health and nutrition examination survey (NHANES) 2007-2012. Am J Kidney Dis 2016; 68(3):414-21. doi: 10.1053/j.ajkd. 2016.03.415.

4. Navari K, Farshidi H, Pour-Reza-Gholi F, Nafar M, Zand S, Pour HS, et al. Spirometry parameters in patients undergoing hemodialysis with bicarbonate and acetate dialysates. Iran J Kidney Dis 2008; 2(3):149-53.

5. Abdalla ME, AbdElgawad M, Alnahal A. Evaluation of pulmonary function in renal transplant recipients and chronic renal failure patients undergoing maintenance hemodialys is Egypt. J Chest Dis Tuberc 2013; 62(1): 145-50. doi.org/ 10.1016/j.ejcdt.2013.04.012

6. Zoccali C, Tripepi R, Torino C, Bellantoni M, Tripepi G, Mallamaci $F$. Lung congestion as a risk factor in end-stage renal disease. Blood Purif 2013; 36(3-4):184-91. doi: $10.1159 / 000356085$.

7. Nakade Y, Toyama T, Furuichi K, Kitajima S, Ohkura N, Sagara $A$, et al. Impact of kidney function and urinary protein excretion on pulmonary function in Japanese patients with chronic kidney disease. Clin Exp Nephrol 2014; 18(5):763-9. doi:10.1007/s10157-013-0920-7.

8. Nascimento MM, Qureshi AR, Stenvinkel P, Pecoits-Filho R, Heimburger $\mathrm{O}$, Cederholm $\mathrm{T}$, et al. Malnutrition and inflammation are associated with impaired pulmonary function in patients with chronic kidney disease. Npehrol Dial Transplant 2004; 19(7):1823-8. doi: 10.1093/ndt/ gfh190.
9. Yoon SH, Choi NW, Yun SR. Pulmonary dysfunction is possibly a marker of malnutrition and inflammation but not mortality in patients with end stage renal disease. Nephron Clinic Pract 2009; 111(1):C1-6. doi:10.1159/000175444.

10. World Medical Association. Declaration of Helsinki: Ethical principles for medical research involving human subjects. JAMA 2013; 310(20):2191-4.

11. Levey AS, Coresh J, Greene T, Stevens LA, Zhang YL, Hendriksen $S$, et al.' Using standardised serum creatinine values in the modification of diet in renal disease study equation for estimating glomerular filtration rate. Ann Intern Med 2006; 145(4):247-54. doi: 10.7326/0003- 4819-145-4200608150-00004.

12. KDIGO CKD work group. KDIGO 2012 Clinical practice guideline for the evaluation and management of chronic kidney disease. Kidney Int Suppl 2013; 3:1-150.

13. Rabe KF, Hurd S, Anzueto A, Barnes PJ, Buist SA, Calverley P, et al. Global strategy for the diagnosis, management, and prevention of chronic obstructive pulmonary disease: GOLD executive summary. Am J Respir Crit Care Med 2007; 176(6):532-55. doi.org/10.1164/rccm.200703-456SO.

14. Mukai $H$, Ming $P$, Lindholm $B$, HeimbuĖrger $O$, Barany $P$, Anderstam $B$, et al. Restrictive lung disorder is common in patients with kidney failure and associates with proteinenergy wasting, inflammation and cardiovascular disease. Plos One 2018; 13(4):e0195585.

15. Covic A, Siriopol D, Voroneanu L. Use of lung ultrasound for the assessment of volume status in CKD. Am J Kidney Dis 2017; 71(3):412-22. doi: 10.1053/j.ajkd.2017.10.009.

16. Kim YS, Kim HY, Ahn HS, Sohn TS, Song JY, Lee YB, et al. Glomerular filtration rate affects interpretation of pulmonary function test in a Korean general population: results from the Korea National Health and Nutrition Examination Survey 2010 to 2012. Korean J Intern Med 2016; 31(6):1101-9. http://doi.org/10.3904/kjim.2015.148.

17. Government of Pakistan, Finance Division. Economic Survey 2005-06 Islamabad: Government of Pakistan Economic Adviser's Wing Finance Division; 2006. http://www. finance.gov.pk/survey/chapters_18/Economic_Indicators_2018 .pdf

18. Anees M, Hussain Y, Ibrahim M, Ilahi I, Ahmad S, Asif K I, et al. Outcome of chronic kidney disease patients on the basis of referral to nephrologist: A one-year follow-up study. J Coll Phy Surg Pak 2018; 28(4):304-7. doi: 10.29271/jcpsp. 2018.04.304.

19. McClellan W, Aronoff SL, Bolton WK, Hood S, Lorber DL, Tang $\mathrm{KL}$, et al. The prevalence of anemia in patients with chronic kidney disease. Curr Med Res Opin 2004; 20(9):501-10. doi.org/10.1185/030079904X2763.

20. Mawani M, Ali SA, Bano G, Ali SA. Iron deficiency anemia among women of reproductive age, an important public health problem: Situation analysis. Reproductive system \& sexual disorders: Current Research 2016; 5(3):1-6. doi: 10.4172/2161-038X.1000187. 